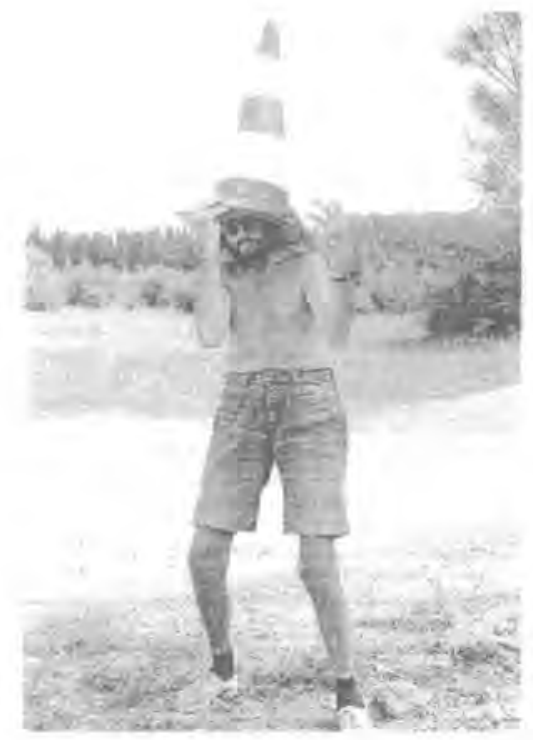

Julio Cortázar entre todos los juegos

Julio Ortega

(Brown University)

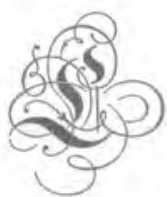

a obra de Julio Cortázar (1914-1984) no parece cómoda en la historia de la literatura (entre los órdenes del pasado), quizá porque su escenario más propio es la actualidad de la lectura (el devenir del presente). Maleable, manual, desarmable, se debe al proceso abierto de su poética operativa. Por eso, disputa el lugar de la literatura entre los discursos normativos y dominantes. No leemos a Julio Cortázar desde la tierra firme nacional, tampoco desde alguna verdad disciplinaria y mucho menos desde la autoridad impositiva del intelectual público. Lo leemos desde la orilla donde el lenguaje se despliega como un cosmos emotivo. En ese devenir de empatía, imantación, asombro y zozobra, el relato se abre. Se proyecta en una próxima página, traza el trayecto de una nueva lectura, afirma el proyecto de otro lector. Hizo del español, como nadie, la materia del habla íntima del reconocimiento mutuo.

Habría que hacerle justicia en una distinta historicidad literaria, la de las obras que no acaban de escribirse, de los libros que no terminan, de las escrituras que recomienzan. Esa fluidez interior nos sitúa fuera del dominio histórico (de la memoria conocida), en el espacio procesal de una nueva lectura, en ese tiempo incesante, sin principio ni final. Esta obra es una constelación en movimiento (de devenir imprevisto), cuyo paso fulgurante nos reconoce no sólo como

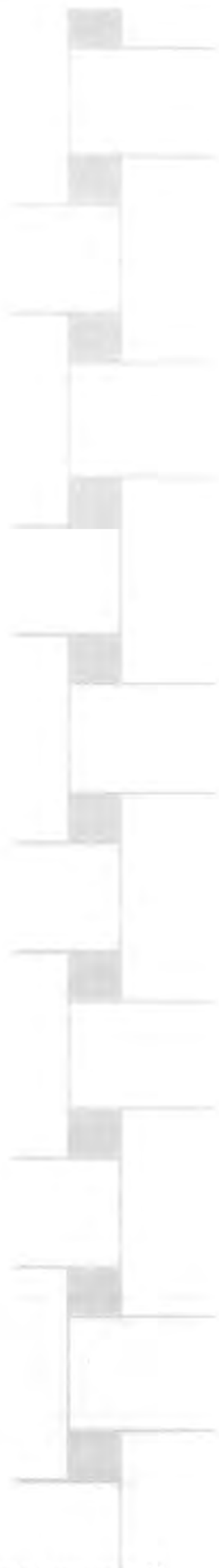


lectores gratificados por la gracia poética, sino como actores a cargo de re-anudar la fábula mayor de la lectura, la de incluirnos. Hablando de esta obra terminamos hablando de nuestro lugar en ella.

Como toda obra mayor, la de Cortázar ha conocido varias etapas de lectura, algunas de ellas previsibles. Primero fue el entusiasmo de lectores cómplices, ligeramente biográficos, que Ilevaban un aura cortazariana. Hubo, soy testigo, una tribu de lectores que deambulan como personajes de un cuento a otro, haciendo méritos de cronopios, y creen formar parte del Club de la Serpiente, el grupo dedicado a la "patafísica" en Rayuela. Otros lectores, más bien académicos, encontraron en esta obra cierta filosofía benéfica, vagamente orientalista $y$, al final, metafísica. Más recientemente, no han faltado lectores que han podido separar al Cortázar de la imaginación fantástica del Cortázar del compromiso político, y han terminado separándose de él. Ignoran que en su obra el lugar del Otro fue siempre una demanda del diálogo. Hasta en los momentos de mayor entusiasmo anarquista, Oliveira descubre que la moral del artista no es individual sino comunitaria. Esto es, el Yo recorre toda la agonía de su búsqueda para encontrarse en el Otro. Tampoco se puede olvidar que en sus textos más políticos reclamó siempre por la imaginación y la diferencia.

En su propio país, aunque había logrado forjar lectores consecuentes, Cortázar fue pronto descartado como cosmopolita por un intenso movimiento anti-cortazariano, que sobre ese gesto de derroche afirmó el valor del nacionalismo. También Borges había sido descartado por un razonamiento paralelo, pero Cortázar fue percibido, si no me equivoco, como más extranjero aún porque había afincado en París y sus referencias locales y hasta su habla porteña resultaban anacrónicas. Pronto, pasó del rechazo al olvido. Sólo los más jóvenes, en Buenos Aires, lo rescataban como un término de referencia interior. Hoy vemos que los mejores continuadores de su proyecto fueron, en primer lugar, Néstor Sánchez, narrador argentino muerto hace poco, quien empezó a escribir a partir de la primera página de Rayuela unas novelas casi olvidadas pero no menos valiosas (como Nosotros dos y Siberia blues), que Cortázar de inmediato reconoció y recomendó. En contra de la conversión dominante a comienzos de los años 70 del escritor en figura pública, Néstor Sánchez optó por un anarquismo radical, se convirtió en clochard, en una suerte de Horacio Oliveira sin relato, en un París sin Rayuela. El gran narrador cubano Antonio Benítez Rojo, cuya aventura de escritor es poco pública y más íntima, se exilió de la Cuba 
por la que Cortázar apostó, pero se forjó un Caribe sin centro y expansivo, como un universo legendario donde situar su obra imaginativa, heredera de ese hechizo de la historia. En sus cuentos de la vida habanera, entre la fluidez cotidiana y el abismo del pasado, Benítez Rojo dialoga fecundamente con los cuentos de Cortázar, y lo hace afirmando su propio diseño. Pero el cortazariano más feliz es Alfredo Bryce Echenique, cuya voz se hizo en la intimidad del diálogo propuesta por el habla de los cuentos del maestro. En esa dicción cálida, dúctil, donde la palabra adquiere el poder de humanizar a los interlocutores, Bryce Echenique forjó su propia entonación, entre el humor bufo y la poesía de los afectos. En La vida exagerada de Martín Romaña puso al revés el programa de Rayuela: París ya no es la fuente propicia sino la tribuna de los latinoamericanos inevitables, llenos de convicciones y ningún remordimiento. El mexicano Juan Villoro, así mismo, reconoce en sus cuentos la gracia poética cortazariana, esa flexibilidad de la forma y plenitud argumental que él maneja, además, dentro de una composición precisa y rica de tensiones anímicas. Cualquier noticia de este linaje tiene que culminar con el argentino Rodrigo Fresán, cuya poética performativa empieza desde la libertad exploratoria y el gusto por el riesgo de la prosa cortazariana; y sigue con el despliegue gozoso de su propio talento. De Cortázar a Fresán, la literatura ha dado la vuelta y nos devuelve un presente ya sin fronteras, liberada al devenir, a esa ganancia de porvenir.

El propio Cortázar entendió que sus lectores habitaban dos hemisferios polares: aquellos que preferían los cuentos eran una tribu distinta a quienes preferian las novelas. Recuerdo la vez que me lo comentó: reconocía ese hecho como una pregunta por su propia obra, deduje, aunque la distinción me pareció retórica; uno podía pasar del cuento a la novela sin pelearse con su sombra. Hoy me parece que Cortázar había intuido alguna divergencia íntima en su propia obra, y que no tenía respuesta para ese dilema. En una página de su La vuelta al mundo... reconoce a la tribu de Rayuela. (A mí me tenía del lado de la novela, y con razón). Probablemente, la diferencia deriva del sistema narrativo divergente. Los cuentos se imponen al lector como suficientes $y$, a veces, perfectos: revelan abismos, carecen de explicaciones, están hechos de asombro y perplejidad, pero su ejecución posee el impulso límpido y el brío tramado de un movimiento musical completo. De cara al trasfondo inexplicable que recuentan, algunos de esos cuentos pueden incluso agotar las explicaciones, y muestran a veces cierta prolijidad de alternativas,
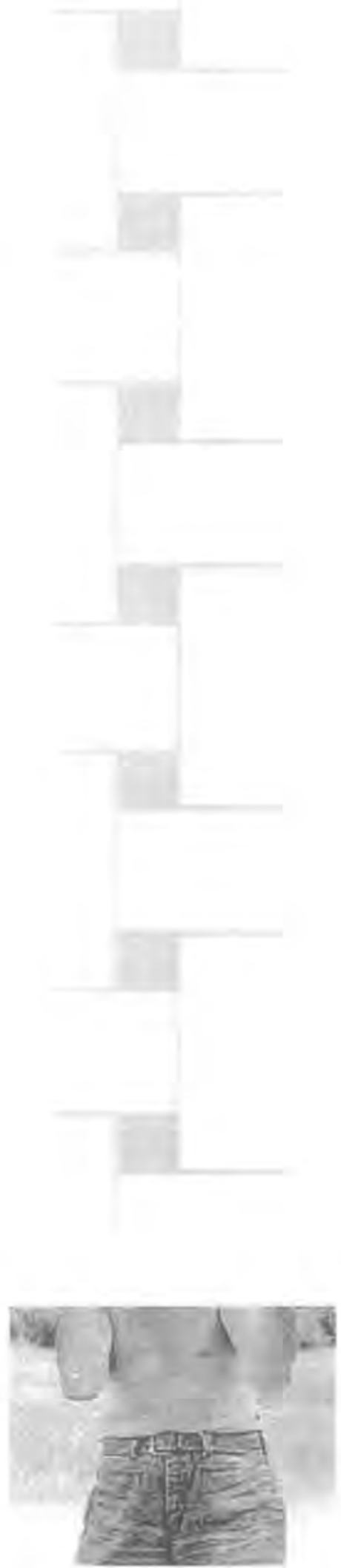
casi la saturación del horror al vacío. Así ocurre en "Axolotl," que prodiga, con gran elocuencia, eso si, posibilidades de sentido común. En cambio, en las novelas, la subjetividad no está del otro lado del lenguaje, encarna de inmediato en la voz. En Rayuela y en 62, modelo para armar; todo está tocado por el arrebato de una voz hecha de vehemencia expresiva, ternura cierta, nostalgia ardida, humor disolvente, y furor poético. La diferencia radica en el sistema: el cuento es el mapa exacto de un asedio; la novela, un proyecto de vida.

Pienso que para evitar una lectura sentimental, por un lado, y filosofante, por otro, ambas saturadoras del desafío que Cortázar nos propone, hace falta leer las convergencias internas de los cuentos y las novelas; esa escritura que excede las obligaciones veristas y los moldes genéricos. Julio Cortázar fue indudablemente un maestro de la sutiliza del cuento y un explorador de la diversificación formal de la novela. También es cierto que muchos de sus cuentos son prosas, estampas, fragmentos, notas, cuya escritura tentativa, fragmentada e imantada, es parte del asedio y la indagación de Rayuela. Para decirlo de otro modo, el cuento pone en tensión lo legible, y dice más de lo que comprueba. En cambio, la novela es una lectura a posteriori, el relato de una aventura de leer (rescribir) lo perdido (vivido) a nombre de lo des-conocido. Pero en ambos casos, la lectura es la dinámica del conocer poético, y discurre entre estaciones de tránsito y albergue, de fusión feliz y disolución dramática. El sujeto recobra, con las palabras, el milagroso instante de su paso.

Ese paso, pasar y pasaje, no es sin embargo una categoría filosófica o metafísica. Ese paseo del ser en el lenguaje es el juego. De por si evidente, esta hipótesis anuncia lo más complejo, sistemático y pasional de una obra que se resiste a acabar, que rehace una y otra vez la partida. Porque en la naturaleza del juego, la variación permanente es el comienzo, ensayado no sólo para abolir el azar sino para abrir, en la saturada nada del azar, el flujo de la coincidencia entre vasos comunicantes. El juego enciende la simpatía del Eros religador y el humor de las grandes causas perdidas.

La obra de Cortázar se puede leer, me propongo demostrar,

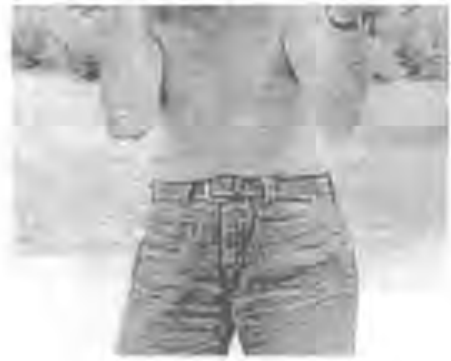
como un plan de juego. Como el proyecto de convertir el juego en la lengua franca de la naturaleza humana, revelada en la gratuidad del juego, despropósito sin propósito. El juego, evidentemente, no es una actividad subsidiaria, paralela u optativa que sigue al "tiempo real," al del valor productivo; tampoco es parte del "tiempo libre," rehúsa ser moneda corriente en la manipulación de los bienes. Más bien, es el 


\section{JULIO CORTÁZAR ENTRE TODOS LOS JUEGOS}

espacio mismo de las revelaciones durables, el diálogo contaminante, y el saber dilapidado.

Si el centro de la obra cortazariana es una teoría y práctica sobre la creatividad, la ampliación de los poderes de invención no se daría sin la innovación poética del juego. Este juego es un lenguaje completo, es decir, una nominación exploratoria (como el gíglico sustitutivo, como el habla cronopia, poco socializada); pero también un ensayo de las inminencias del deseo. Sin valor de uso, esa actividad fugaz del juego (cambiante y deseante) es, sin embargo, capaz de recusar todos los órdenes en su radicalidad gratuita, talante demiúrgico, y pasión aleatoria. Por eso, la creatividad de Cortázar es del signo más fecundo: su curiosidad recupera el brío de las cosas en su nuevo orden, el de una productividad lúdica.

Esta economía del juego se reproduce a partir de una noción paradójica, la del desvalor de los signos más creativos. Así, la miga de pan que rueda bajo la mesa del restaurante, los piolines que se encuentra en los bolsillos, el paraguas roto al que se da entierro, configuran la serie de los objetos sin finalidad ("cosas inútiles"). Son sílabas de un discurso desanudado por su no utilidad. Son signos sin otro significado que el residual en el espacio derivado y contrario del juego. Y sin embargo, con estos signos mínimos Rayuela construye un lenguaje de inquietante poder, que abandona el Archivo genealógico y se proyecta hacia un futuro reanudado por los ritos de purificación del juego. Los cronopios, se diría, pertenecen al nuevo cronos, donde se habla la lengua pía, la de los pájaros libres. Al final, el lenguaje del juego trama, a modo de ejemplos, la puesta en duda de los discursos dominantes. Esos micro-relatos configuran, por así decirlo, lugares tentativos del juego, donde refulge su humor liviano y proyecto irónico.

Los breves lugares del juego, pasajes y umbrales irrepetibles, donde tienen lugar el azar subjetivo, el goce estético, el diálogo contra rutina, adquieren el trámite distintivo de su gratuidad. Acontecen en su teatro pasajero, fugazmente, como una ceremonia intensa, casual y nostálgica. Los repetidos tablones que son un puente irrisorio no dejan de ser, primero, una cuerda del malabarismo emocional. Estos objetos carecen de lugar en el mercado, no tienen clientes ni valor de uso; y sólo tienen la forma instantánea de un valor de juego. No son símbolos de otro discurso, son signos de un próximo discurso, pedrusco fundador del camino. La "rayuela" misma, ese dibujo en la acera, que se juega con un guijarro y cuyos saltos entre casillas religa la tierra y el cielo, es una figura casual y momentánea, cuyo valor lo
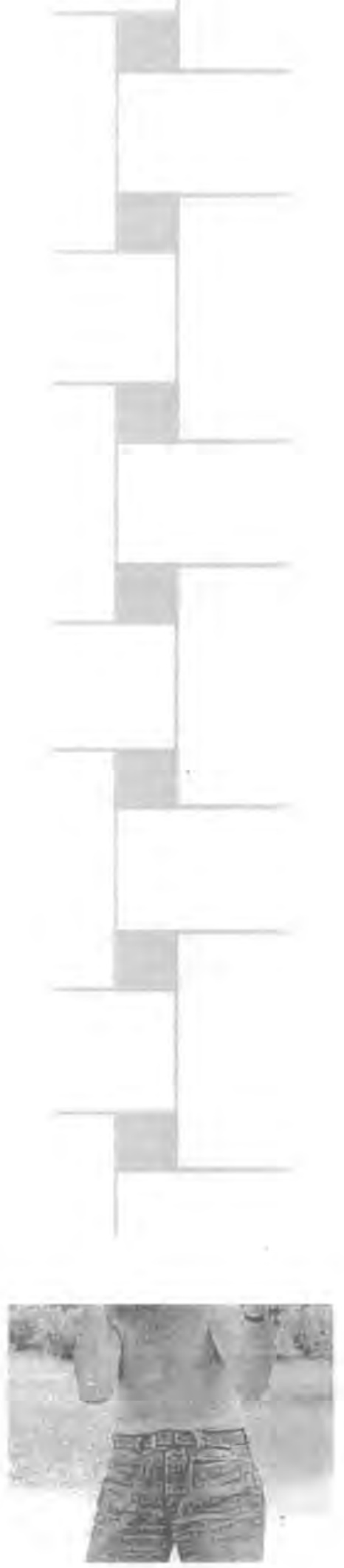


\section{JULIO ORTEGA}

dicta la duración del juego, esto es, la temporalidad pura del espectáculo. La novela se llamó primero "Los juegos," después "Mandala," y por fin "Rayuela." Aunque, en sus cartas a Francisco Porrúa, prefiera llamarla "contranovela." De uno a otro nombre, se impone la gratuidad de un mapa del juego.

Pero la economía simbólica de los materiales del juego se articula en el relato como una opción radical por una definición estética de vida. A comienzos de los años 60 , Cortázar construyó su novela-instrumento como el espacio donde hacían "rayuela," donde se articulaban "casillas" provisorias y periódicas, por un lado la consagración de la ciudad favorable y el principio de la improvisación ilustrado por el jazz; y, por otro lado, el relato auto-reflexivo, que se hace leer desde dentro para desatar todas sus referencias y cederlas a la novela por venir, a la literatura por hacerse, al lector por forjarse. Este plan de liberación no ignora la caída y el sacrificio, pero tampoco el placer de lo nuevo, el estremecimiento de un tiempo que da la vuelta al final de la historia vivida, convertido en relato actual de todos los lenguajes barajados.

Quiero decir que la novela es el mayor juego: empieza cuando todo ha terminado, como el recuento de sí misma y como el proyecto de otra novela. Esa otra novela radicalmente nueva, es convocada aquí como la imagen en el espejo de Morelli: se cruza de ida con la novela que viene de más lejos. Esto es, leemos la novela como la peregrinación de Oliveira aunque sabemos que su aventura ha terminado cuando empieza el relato, porque quien habla en la novela es una voz que regresa para recuperarse en la escritura. El "yo" de Oliveira es Morelli, el "otro" radical. La novela por hacerse es la imagen de la novela que leemos. Los "lectores" que descifran lo cuadernillos de Morelli se leen a sí mismos, y los leemos leyéndonos. Hasta la Maga es la heroína de otro relato, el proyecto de una Quimera convocada. Así, los tiempos de la historia (la memoria del relato) no corresponden a los tiempos de la escritura (la suma de las restas) porque lo decisivo no es la experiencia de un sujeto sino la puesta en página de la voz, esa vasta empresa narrativa construida como un libro inventado, creciente, incompetable.

Como sabemos, Cortázar ensayó siete u ocho posibles ordenamientos de los fragmentos que había escrito como una protonovela, cuya lectura lineal le resultaba episódica y poco radical. Primero pensó en una novela de hojas sueltas que se mezclaran en una caja. Pronto le resultó una fórmula previsible, de tinte vanguardista. Luego imaginó cuadernillos según los personajes, capítulos 
serializados, progresiones argumentales. Hasta que por fin, jugando con distintos ordenamientos, descubrió el principio de la remisión (cada capitulillo remite a otro), la práctica combinatoria (la lectura a saltos es una "rayuela" de sumas contrapuestas con humor por la prosa asociativa y fluida); y, por fin, la "resta" de la lectura (que descuenta de la idea del Libro cada capítulo/ casilla, al modo de una figura rotante y gozosa. Leer Rayuela es uno de los grandes placeres del lenguaje.

Pero estas afirmaciones vitales, estéticas y hasta morales, no eran un programa inculcado sino un desarrollo argumental. Por eso, para el equilibrio de los pasos del juego, son tan importantes los paisajes y personajes que encarnan el no-juego, aquellos que oponen una negatividad contraria. Me refiero a dos grandes áreas opuestas a la creatividad; primero, lo inauténtico (los artistas pomposos, las señoras prominentes, "amigas del arte y medio putonas"); $y$, después, la Gran Costumbre (la vida cotidiana cuya subjetividad ha sido ocupada por la reproducción social, por la mercancía que dicta la forma del deseo). El juego es un alegato contra la sociedad como maquinaria normativa, y contra el sistema de producción capitalista capaz de convertir a la mercancía en la forma de la amnesia, como decía Adorno. Benjamin adelantó que la forma de la mercancía adquiría en Baudelaire el conteni ioo social de una alegoría de la percepción (Arcades project, 335), y que la pérdida del "aura" del poeta se debía a que el mercado reproducía masivamente la imagen. Rayuela responde a esas homologías modernistas desde una refutación radical de los poderes disuasivos del mercado y su usurpación de la subjetividad. Pero en lugar de recaer en un tardío anticapitalismo romántico, Cortázar desarrolla la práctica de una contra-producción en los márgenes del mercado (la "contranovela"). Frente a la reproducción, asume el carácter precario de los signos inútiles para construir su rebelión de cosas, o sea, su gran juego rebelde; y contra el mercado, introduce el valor de la emotividad como principio de lo genuino indeterminado.

Incluso en Libro de Manuel (1973), donde el relato buscaba hacer coincidir al "homo faber" con el "homo ludens," el juego se despliega como una estrategia mediadora: "Yo sé jugar sola pero ahora es otra cosa, un juego que a lo mejor puede servir para algo, nunca se sabe," dice Ludmilla, ante la mirada irónica de Andrés (160). El fracaso de la empresa del relato político se convierte en la moral del juego: "el juego es grande y yo creo que vale la pena, total ganar o perder no tiene importancia en sí..." (235), concluye "el que te dije," el
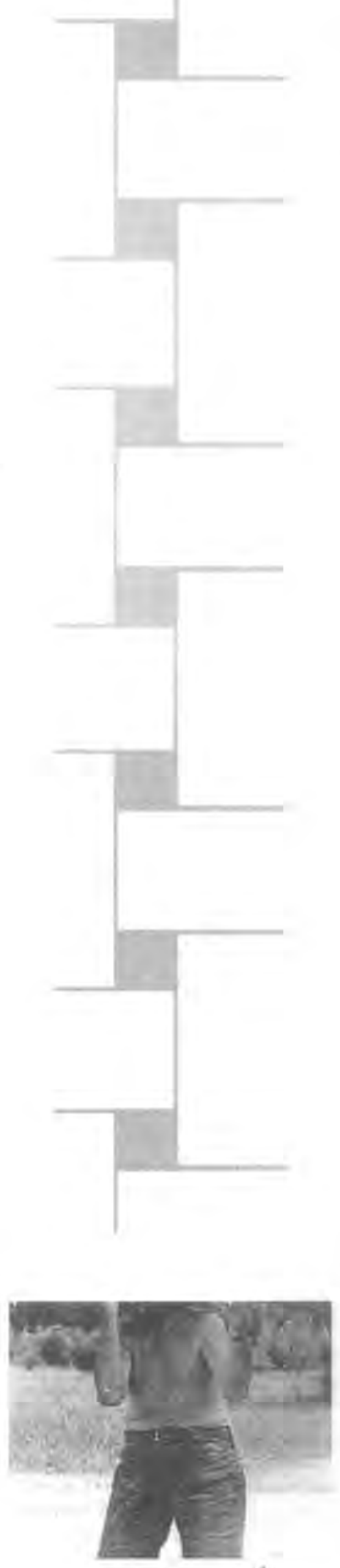
Narrador. Pero en esa novela el juego se ha hecho instrumental, y su función es otra, la de desplegar las contradicciones.

Sin valor y sin autoridad, en Rayuela el juego ocurre fuera de las representaciones sancionadas como referenciales por el lenguaje; fuera, quiero decir, de su valor de cambio e intercambio entre oferta y demanda. Bien visto, se trata de una economía del exceso sin valor, esto es, del deseo subversivo que caracteriza a la práctica anarquista. Por eso, entre la "patafísica" (que recicla los objetos del arte como precarios) y el anarquismo (la rebelión contra la socialización burguesa), el sistema de producción de Rayuela es un modelo de crítica y poética, de pensamiento libérrimo y emotividad artística. Se alimenta, es cierto, del culto del "azar objetivo" y los "objetos hallados" que prodigó el surrealismo; pero está libre tanto del coleccionismo de Breton (después de todo un marchant de arte moderno) como del gabinete de las vanguardias. Hasta el gusto por los "piantados" revela la empatía del proyecto con el desvalor de lo irrisorio, con la rareza inquietante de una racionalidad totalizadora y, por eso, tan atractiva como ilusa. En una carta a Porrúa, cuando se está componiendo Rayuela, Cortázar le pide añadir alguna nota que advierta al lector que Ceferino Piriz es real, que no ha sido inventado por el autor. Inventado, sería creíble; real, es increíble, casi inverosímil. El "piantado" es un genio al revés, el otro lado de la creatividad, su desvarío. Pero como para evitar que su programa tenga respuesta y se ilustre a sí mismo, incluso la idea de la Novela que habita en Rayuela es una demanda: una novela por hacerse, planeada especulativamente por Morelli, autor muy interior, cuyos personajes lo leen como si pasaran a través del espejo, del lado que nos incluye.

De modo que Rayuela se debe a ese proyecto utópico de una novela capaz de jugarse la vida en su valor universal sin precio.

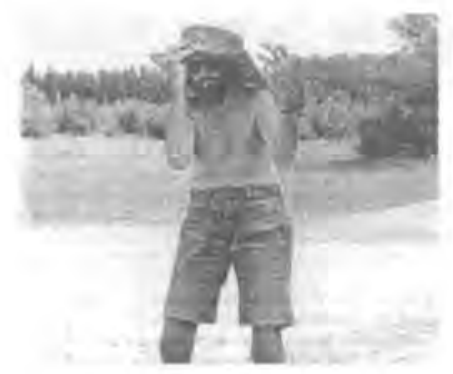

